\title{
Epimacular brachytherapy for wet AMD: current perspectives
}

\author{
This article was published in the following Dove Press journal: \\ Clinical Ophthalmology \\ 30 August 2014 \\ Number of times this article has been viewed
}

\author{
Ricardo P Casaroli- \\ Marano ${ }^{1,2}$ \\ Socorro Alforja' \\ Joan Giralt' \\ Michel E Farah² \\ 'Instituto Clínic de Oftalmología \\ (Hospital Clínic de Barcelona), \\ University of Barcelona, Barcelona, \\ Spain; ${ }^{2}$ Department of Ophthalmology \\ and Visual Sciences, Universidade \\ Federal de Sao Paulo, Escola Paulista \\ de Medicina, Sao Paulo, Brazil
}

\begin{abstract}
Age-related macular degeneration (AMD) is considered the most common cause of blindness in the over-60 age group in developed countries. There are basically two forms of presentation: geographic (dry or atrophic) and wet (neovascular or exudative). Geographic atrophy accounts for approximately $85 \%-90 \%$ of ophthalmic frames and leads to a progressive degeneration of the retinal pigment epithelium and the photoreceptors. Wet AMD causes the highest percentage of central vision loss secondary to disease. This neovascular form involves an angiogenic process in which newly formed choroidal vessels invade the macular area. Today, intravitreal anti-angiogenic drugs attempt to block the angiogenic events and represent a major advance in the treatment of wet AMD. Currently, combination therapy for wet AMD includes different forms of radiation delivery. Epimacular brachytherapy (EMBT) seems to be a useful approach to be associated with current anti-vascular endothelial growth factor agents, presenting an acceptable efficacy and safety profile. However, at the present stage of research, the results of the clinical trials carried out to date are insufficient to justify extending routine use of EMBT for the treatment of wet AMD.
\end{abstract}

Keywords: macular degeneration, radiation, vascular endothelial growth factor, combined therapy, intravitreal therapy, vitrectomy

\section{Introduction}

Age-related macular degeneration (AMD) is the most common cause of vision impairment among people over 60 years of age. In 2010, the World Health Organization estimated that 285 million people were visually impaired. Of these, 246 million had low vision, and 39 million were primarily legally blind due to cataract, glaucoma, and AMD. ${ }^{1}$

Epidemiological data on this disease in the European population suggest that $1.7 \%$ of adults over 55 years may have the condition in its more advanced clinical forms, and draw attention to the major social and health problems that this situation may create in certain populations with high life expectancy. ${ }^{2}$ Data from a meta-analysis revealed that the prevalence of AMD in the European population aged between 65 and 75 years ranges between $9 \%$ and $25 \%{ }^{3}$ This prevalence is slightly higher in women $(1.03 \%)$ than in men $(0.90 \%)$ between the ages of 65 and 69 years and increases with age, reaching $2.36 \%$ among women aged between 70 and 74 years. ${ }^{3}$ However, the results obtained in different studies of AMD prevalence vary considerably: in one meta-analysis of Caucasian populations, $20 \%$ of the variability in prevalence rates was explained by the marked differences in age, and $50 \%$ by study design characteristics. ${ }^{4}$ Meanwhile, there is an exponential increase in the AMD prevalence among age groups analyzed - as much as $4.2 \%$ per decade - with no sex differences, although there is some evidence to suggest an increased risk $(\times 1.2)$ for occurrence in women. Overall, it
Correspondence: Ricardo P

Casaroli-Marano

Instituto Clinic de Oftalmología,

Calle Sabino de Arana I, E-08028

Barcelona (Spain)

Tel +34 932275667

Fax +34 932275662

Email rcasaroli@ub.edu 
is estimated that the prevalence of AMD is $1.4 \%$ at 70 years of age, rising to $5.6 \%$ at 80 years and $20 \%$ at 90 years. ${ }^{4,5}$ In the US, a population-based study (the Beaver Dam Study) of persons aged between 43 and 86 years found a 14.3\% 15 -year cumulative incidence of early clinical presentation of AMD and a 3.1\% incidence of late AMD at baseline. ${ }^{6}$ In the over-75 group, the 15-year cumulative incidence of late AMD was $8 \%$.

Population-based meta-analyses have shown prevalence of early and late AMD in Caucasian populations aged over 40 years of around $6.8 \%$ and $1.5 \%$, respectively. ${ }^{7}$ Regarding ethnicity, the results of the Baltimore Eye Survey showed that the prevalence of advanced AMD clinical forms was nine-fold higher in Caucasians than in African-Americans. ${ }^{8}$ Recently, the prevalence of the advanced forms of AMD has been found to be similar between Asians and Caucasians. ${ }^{9}$ In the Latin American population, various studies have reported prevalence ranging from $2.4 \%$ to $16.4 \%$ in the population aged over 50 years with visual acuity less than $20 / 200{ }^{1}$

From the clinical point of view, AMD has two forms of presentation: geographic (dry or atrophic) and wet (neovascular or exudative). The former may represent approximately $85 \%-90 \%$ of ophthalmic frames of disease and is characterized by a slower but progressive degeneration of the retinal pigment epithelium (RPE) and the photoreceptors. Wet AMD, which accounts for only $10 \%-15 \%$ of clinical forms, causes the highest percentage of central vision loss due to disease. The neovascular form appears due to an angiogenic process in which newly formed choroidal vessels (choroidal neovascularization; CNV) invade the macular area. ${ }^{10,11}$ In the geographic form, the pathophysiological mechanism has yet to be clarified, but it is thought that it may be a chronic inflammation mechanism involving several factors associated with the activation pathways of complement factors and oxidative stress. ${ }^{11,12}$

Today there is ample scientific evidence to suggest that the vascular endothelial growth factor (VEGF) plays a key role in the pathophysiology of wet AMD. ${ }^{13-15}$ These findings have ushered in a new era in the treatment of CNV, based on a better understanding of the cellular and molecular mechanisms associated with disease. Anti-angiogenic drugs, used to block the different stages of the VEGF action pathways, represent a major advance in the treatment of wet AMD. Pegaptanib sodium (Macugen ${ }^{\circledR}$; Eyetech/Pfizer Inc.) was the first drug developed for intravitreal treatment of wet AMD. It is a polyethylene glycol aptamer synthesized from RNA oligonucleotides which binds selectively with high affinity and specificity to the VEGF-A ${ }_{165}$ isoform, thus preventing recognition of VEGF by its receptor. ${ }^{16}$ Ranibizumab (Lucentis ${ }^{\circledR}$; Genentech Inc./Novartis Pharma AG) is a humanized Fab fragment of a recombinant monoclonal antibody (RhuFabV2), which is designed to block all isoforms of VEGF-A. Due to its lower molecular weight $(\sim 48 \mathrm{kDa})$, following intravitreal administration it easily penetrates through the different layers of the retina and exerts an inhibitory effect on vascular permeability and angiogenesis. ${ }^{17}$ Bevacizumab (Avastin $^{\circledR}$; Genentech Inc./ Roche) is a humanized recombinant monoclonal antibody (RhuAbV2), which also inhibits all isoforms of VEGF-A in a nonselective manner. Although the use of this drug is approved for intravenous treatment of some advanced and metastatic carcinomas, its repeated intravitreal administration in wet AMD cases also demonstrates the ability to reduce vascular exudation and block CNV. ${ }^{18}$ More recently, aflibercept (Eylea ${ }^{\circledR}$; Regeneron Pharmaceuticals Inc./Bayer) - a fusion protein with specific high affinity binding to the VEGF receptor domains (VEGF-A and VEGF-B) and the placental growth factor (P1GF-1 and PlGF-2) - demonstrated its clinical safety and efficacy to suppress CNV in patients with the neovascular form of AMD, and its durability of action relative to other intravitreal anti-VEGF. ${ }^{19}$ However, at present, there are no specific and efficient treatments for the advanced form of dry AMD or for its effects on macular area structure and function.

In spite of the significant therapeutic advances made in recent years, several areas of concern still remain: for instance, the social impact of the disease, its cost in relation to the treatment and its benefits, the ability of public health care services to organize appropriate clinical monitoring, and the need for standardized protocols of action relating to therapeutic aspects of the disease, specifically the periodic repetition of the intraocular injections. Options for reducing the frequency of repeated intravitreal injections are being explored, such as combined treatment with photodynamic therapy (verteporfin) or radiation therapy (proton therapy, stereotactic radiation, and epimacular brachytherapy), which seem scientifically plausible due to their synergistic effects. However, the problems mentioned have not yet been resolved, and are compounded by the irrefutable fact that global life expectancy is increasing, especially in populations in the industrially developed countries and in emerging economies.

Advanced age is the main risk factor for AMD. More than $10 \%$ of people over age 80 have widespread forms of the disease. ${ }^{20,21}$ Ocular risk factors are a light-colored iris, prior cataract surgery, and hyperopia. ${ }^{11,22}$ One meta-analysis 
suggested that cataract surgery is a significant added risk for the onset of AMD, although this association has not been conclusively demonstrated..$^{22}$ General and systemic risk factors include smoking, obesity, excessive sun exposure, and cardiovascular disease. ${ }^{11}$ Cigarette consumption is a particularly important risk factor, and in fact is the only preventable one. ${ }^{22}$ Recently, cardiovascular risk factors have also been associated with the development of pathology; people with AMD also have a higher risk for cardiovascular disease and a predisposition to stroke. ${ }^{11,23}$ So the potential risk factors are 1) age, 2) smoking, 3) family history and genetic predisposition (certain genetic polymorphisms are associated with an increased risk of the disease), 4) sex (women seem to be more prone to develop the disease), 5) ethnicity (the prevalence is higher in Caucasian populations), 6) hypertension and cardiovascular disease, 7) light-colored iris (blue eyes), 8) excessive exposure to sunlight (ultraviolet radiation), 9) poor nutritional states (intake of antioxidant supplements [vitamins C, E, and zinc], carotenoids [lutein and zeaxanthin], and polyunsaturated essential fatty acids, long-chain [omega-3] prevent development to more advanced stages of the disease), and 10) obesity (high correlation of the disease with high body mass index). ${ }^{20-24}$

Although AMD is still considered a complex multifactorial disease with a heterogeneous phenotype, a genetic predisposition has been established in AMD patients. It is believed that the association of environmental factors and the involvement of different genes increase the predisposition for disease onset. ${ }^{25-30}$ Currently, several candidate genes are under investigation as inductors or protectors related with pathology. ${ }^{25,27,29,30}$ So AMD can be seen as the product of environmental factors and genetic predispositions. ${ }^{31}$ The study of gene polymorphisms may help to identify patients and families at high risk for the disease, and to establish an adequate response to treatment. ${ }^{25,30}$ These are emerging fields of great translational interest today.

\section{AMD pathogenesis}

The findings regarding molecular aspects of the biochemical and cellular pathophysiology of AMD suggest that the complex formed by photoreceptors, RPE, Bruch's membrane, and choriocapillaris creates a local predisposition to continuous oxidative stress, which is more pronounced in the macular region. ${ }^{32-34}$ Oxidative stress encourages the occurrence of an inflammatory process mediated in part by the complement activation, mainly at the level of the RPE/Bruch's membrane junction. Patients with mutations in these proteins in the complement system components are less able to modulate the inflammatory response, resulting in constant, excessive cell damage with accumulation of extracellular waste, whose main histopathologic feature is the formation of drusen. ${ }^{34}$ These changes involve the modification of the extracellular matrix and contribute to the maintenance of the inflammatory process by causing additional cellular damage. This chronic inflammatory response involves cellular components of the immune system and the classical and alternative pathways of the complement system (C2 and C3 complements, complement factor $\mathrm{H}$ and complement factor B). ${ }^{35-38}$ Progressive accumulation of abnormally metabolized extracellular material, including cell membrane debris (the RPE's phagocytic function), oxidized molecules (reactive oxygen products and oxidative stress), degraded extracellular matrix molecules, and the components of the complement system (activation of inflammatory mechanisms) is therefore a sign of the damage caused by a chronic inflammatory process. The initial clinical manifestation of this inflammation is the appearance of drusen (accumulation of cellular waste material) and pigmentary changes (EPR degradation from accumulating lipofuscin), which over time, promotes the development of clinical manifestations of late stages of AMD in susceptible individuals (eg, atrophy and/or CNV). However, the role of choriocapillaris in the pathogenic cascade is not fully elucidated. Various treatments for AMD are currently under investigation, based on concepts related to this hypothesis of pathogenesis.

Thus, the evidence indicates that AMD is associated with oxidative damage, accumulation of lipofuscin inside RPE cells, chronic inflammation, and genetic mutations in certain proteins in the complement system. Various molecular targets have been identified that can serve as a basis for developing potential new treatments for the disease, including preventive treatments for early clinical forms and others for rescue, replacement, and regeneration in order to address complications in the late stages of geographic atrophy forms or structural alterations following $\mathrm{CNV}$ in the macular area.

\section{Radiation and CNV}

Several approaches have been effective in the treatment of $\mathrm{CNV}$ in the macular area, including laser treatment, photodynamic therapy with veterporfin, and most recently, antiVEGF antibodies and fusion proteins, which have evolved considerably over the past two decades. ${ }^{39,40}$ Whereas treatment modalities such as thermal laser photocoagulation and photodynamic therapy have been applied in selected cases of CNV in AMD and have yielded modest results in terms of improvement of vision, the introduction of drugs that directly 
inhibit VEGF action has provided better visual prognosis. Combined therapies and association with intraocular steroids are also valid strategies. ${ }^{40}$

Radiation therapy has previously been studied as a treatment for solid vascularized intraocular tumors and wet AMD. ${ }^{41,42}$ Radiation is used to treat tumor cells and the formation of new vessels for solid vascularized tumors in much the same way as in a proliferative wound healing process, because cells with high rates of proliferative activity are sensitive to the effects of ionizing radiation. ${ }^{43,44}$ Histologically, the newly formed CNV complexes are composed of RPE and endothelial vascular cells, connective cells (fibroblasts), and local inflammatory cell populations (macrophages and plasmatic cells). ${ }^{45}$ Initially, the use of ionizing radiation for the AMD treatment was partially limited by the inevitable collateral damage to adjacent healthy ocular tissue deriving from the application of radiation through transscleral (sclera, choroid, and choriocapillaris) or transcorneal (cornea and lens) techniques to treat macular $\mathrm{CNV} .{ }^{42}$ In the treatment of posterior choroidal melanoma by plaque brachytherapy, the total radiation doses that may lead to complication rates between $5 \%$ and $50 \%$ (at 5 years) are expressed by the tissue tolerance dose (TD) as TD5 and TD50, respectively. For the retina, TD5 and TD50 are 45 Gy and 65 Gy, respectively, suggesting that doses of 45 Gy-50 Gy can be safely tolerated by the foveal region. ${ }^{46,47}$

More recently, approaches for delivering radiation therapy to retinal and subretinal tissues have been refined in the form of epimacular brachytherapy (EMBT; Vidion Neovista, Inc., Newark, CA, USA) and stereotactic radiotherapy (teletherapy; IRay, Oraya Therapeutics, Inc., Newark, CA, USA), which deliver radiation focally or directionally to the neovascular lesion in the macula, while minimizing exposure of the neighboring healthy retina and other surrounding ocular tissues. The stereotactic radiotherapy uses a low-voltage $\mathrm{X}$-ray system with a great advantage of not requiring invasive surgical procedures such as a pars plana vitrectomy, which is necessary in EMBT approach.

The mechanism of action of radiotherapy in CNV in AMD is based on selective inhibition of the proliferation of endothelial cells of newly formed capillaries without affecting the cell activity related to the tissue repair mechanisms. ${ }^{48}$ Drugs which block VEGF, are effective in limiting the increased vascular permeability of CNV but they are not usually able to achieve CNV regression. CNV presents a different behavior from the normal surrounding native vasculature, characterized by uncontrolled growth and increased permeability. Radiation leads directly to capillary closure, which may be the reason for its efficacy in reducing bleeding. ${ }^{49}$ Histopathological findings suggest that endothelial cell loss may occur up to a year after irradiation. ${ }^{50}$ The apoptotic effect of radiation is mainly the result of the direct action on the cellular DNA. Radiation significantly alters the nuclear DNA, leading to ruptures in the single or double strands and disturbing the purine base pairs. These changes affect cell division and directly modify the cell cycle. ${ }^{51}$ The radiation also interacts with other atoms or molecules inside the cell (particularly water) creating free radicals and reactive oxygen products (ROS). These free elements induce additional indirect DNA damage. ${ }^{46}$ Other additional effects include the inhibition of cells responsible for the synthesis and secretion of pro-inflammatory growth factors and for modulating cell types related to scar tissue formation. The anti-inflammatory properties of radiation therapy may be desirable, since inflammatory events are the dominant factor in the progression of AMD and contribute to $\mathrm{CNV}$ development. A reduction in macrophage-mediated retinal inflammation has been demonstrated after irradiation. ${ }^{52}$ The final property of radiation treatment is its anti-fibrotic effect. ${ }^{53}$ Radiation therapy may inhibit CNV metaplasia due to endothelial cell apoptosis that leads into fibrotic glia (disciform scar). Additionally, radiation may arrest the fibrovascular growth component induced in the angiogenic process. ${ }^{54,55}$ Thus, radiation has anti-angiogenic, anti-inflammatory, and anti-fibrotic effects.

The biological effect of ionizing radiation is the principle of ionization, in which the absorption of energy by an atom or molecule results in the ejection of one or more of its orbiting electrons, resulting in unstable and highly reactive compounds. Brachytherapy has been used with either palladium-103 $\left({ }^{103} \mathrm{Pd}\right)$ or strontium $\left({ }^{90} \mathrm{Sr}\right)$. Dosimetric studies have shown that localized application dispenses a much lower dose of radiation to the lens and the optic nerve, leading to external-beam therapy, thus significantly reducing adverse effects in these structures. Previous studies showed a dose on the target tissue of between 5 Gy and 24 Gy. ${ }^{55,56}$ Beta radiation is composed of particles with a mass similar to that of electrons and gives a greater penetration power. However, beta radiation stops at a few meters of air or at a few centimeters of water, or biological tissue, meaning that it is very useful for surface radiation treatments in which deeper tissue penetration is undesirable. The penetration depends on the energy of the particles released in the decay process of a particular source. Strontium-90 has been found to be a clinically useful source of beta radiation because it emits only high-energy beta particles as it decays. Ruthenium-106 
$\left({ }^{106} \mathrm{Ru}\right)$ primarily emits beta radiation but also emits a small but significant degree of gamma irradiation. ${ }^{57}$ The half thickness of ${ }^{90} \mathrm{Sr}$ is $1.5 \mathrm{~mm}$ (this represents the radiation dose rate, which is attenuated by $50 \%$ after $1.5 \mathrm{~mm}$ penetration through water). The corresponding distance for ${ }^{106} \mathrm{Ru}$ is $2.4 \mathrm{~mm} .{ }^{43}$ Therefore, among the emitters used in ophthalmology, ${ }^{90} \mathrm{Sr}$ has the most marked attenuation in biological tissues, making it particularly suitable for ocular use.

\section{Epimacular brachytherapy in AMD}

Radiation therapy is currently under investigation again, in combination with anti-VEGF therapy for wet AMD (Table 1). Radiotherapy often produces a delayed response but retains one of its benefits - a much longer duration of action. ${ }^{51}$

EMBT, which was developed to deliver intraocular radiation, places the source of radiation close to the CNV complex in the macular region. The beta radiation dose declines rapidly with increasing distance from the source, limiting radiation exposure and mitigating the damage to adjacent normal tissue. ${ }^{51,58}$ The beta radiation used in EMBT is delivered via a pars plana vitrectomy with the removal of the vitreous body and the positioning of a probe over the CNV lesion. The end of the probe contains a source of ${ }^{90} \mathrm{Sr} /$ Yttrium-90 radiation. The device is held in position for approximately 5 minutes, long enough to deliver 24 Gy to the CNV complex. A preoperative macular fluorescein angiogram is normally used to determine the area of greatest disease activity. Because beta radiation decreases with increasing distance from the original source, the optic nerve receives approximately $2.4 \mathrm{~Gy}$, and the lens only $0.56 \mathrm{mGy}$ - far below the level of 2 Gy considered the threshold for cataract formation. ${ }^{51,59}$ Cataract formation after vitrectomy is also a common feature and has been described in $80 \%$ of eyes 2 years after the procedure. ${ }^{60}$ Furthermore, vitrectomy itself may be helpful in treating AMD, since it limits vitreomacular adhesion. ${ }^{61}$ It has also been suggested that the removal of the vitreous gel increases the level of oxygen available to the inner layers of the retina via better diffusion from the aqueous humor. ${ }^{62,63}$ In addition, by increasing the oxygenation in the macular area, it may increase the formation of free radicals and therefore facilitate the degradation of cellular double-stranded DNA and prevent further CNV formation. ${ }^{51,64}$

In the initial feasibility study, 34 patients received 24 Gy for 5 minutes and were followed up for 3 years. ${ }^{65,66}$ Approximately $90 \%$ of eyes lost fewer than 15 letters from baseline, and $21 \%$ gained more than 15 letters. In these clinical trials, patients received an anti-VEGF injection at the time of surgery and again 1 month later. ${ }^{65}$ Thereafter, they received
anti-VEGF therapy as PRN (pro re nata [as needed]) protocol, based on disease activity. ${ }^{66}$ Radiation treatment dramatically reduced the need for anti-VEGF therapy, with only eleven eyes requiring additional bevacizumab retreatment therapy over 3 years for a mean of three injections in all. ${ }^{66}$ The potential risks of intraocular radiation include retinopathy, optic neuropathy, and cataract. There were no severe radiationrelated adverse events, and $50 \%$ of phakic eyes experienced cataracts (Table 2).

These results were the basis for prospective, randomized controlled trials including treatment-naïve individuals (MERITAGE and CABERNET) and in individuals already treated with anti-VEGF therapy (MERLOT). ${ }^{40,58}$

The MERITAGE trial targeted patients with chronic active AMD who already required frequent injections of anti-VEGF therapeutics. ${ }^{67,68}$ Fifty-three eyes (53 patients) previously treated for wet AMD with repeated anti-VEGF therapy were also treated with single 24 Gy dose via EMBT $\left({ }^{90} \mathrm{Sr} /\right.$ Yttrium-90 source) and were then followed up with monthly ocular coherence tomography. Participants were retreated with ranibizumab, administered monthly as PRN protocol. Before enrolment, the average rate of anti-VEGF injection was 0.45 / patient/month; during the 12-month follow-up period, the rate of retreatment was $0.29 /$ patient/month. ${ }^{67}$ Recent results at 24 months showed that $68.1 \%$ of participants lost fewer than 15 letters, with a mean of 8.7 ranibizumab retreatments. ${ }^{68}$ Common adverse events included conjunctival hemorrhage $(71.7 \%)$ and cataract $(30.2 \%)$. There was one case of nonproliferative radiation retinopathy in the 24 months of followup $^{68}$ (Table 2). Overall, these results suggest that combination therapy with EMBT can stabilize wet AMD, thus decreasing the requirement for anti-VEGF therapy. However, the apparent reduction in ranibizumab retreatments was less evident over 24 months than during the first year, and a moderate reduction in visual acuity persisted after 24 months of follow-up.

In the CABERNET trial, 494 treatment-naïve wet AMD patients were enrolled in a 2:1 randomization scheme to receive either 24 Gy of radiation with two monthly loading injections of ranibizumab, followed by ranibizumab as needed. ${ }^{69}$ The control arm received three monthly loading injections of ranibizumab, followed by quarterly injections in a modified PIER protocol. ${ }^{54}$ Both arms also received monthly PRN retreatment. CABERNET was a prospective trial with a non-inferiority outcome. Over 24 months, EMBT did not meet the superiority endpoint for the proportion of participants gaining more than 15 letters (16\% for the EMBT group versus $26 \%$ for the control group). This difference was statistically significant (in favor of controls) for occult 


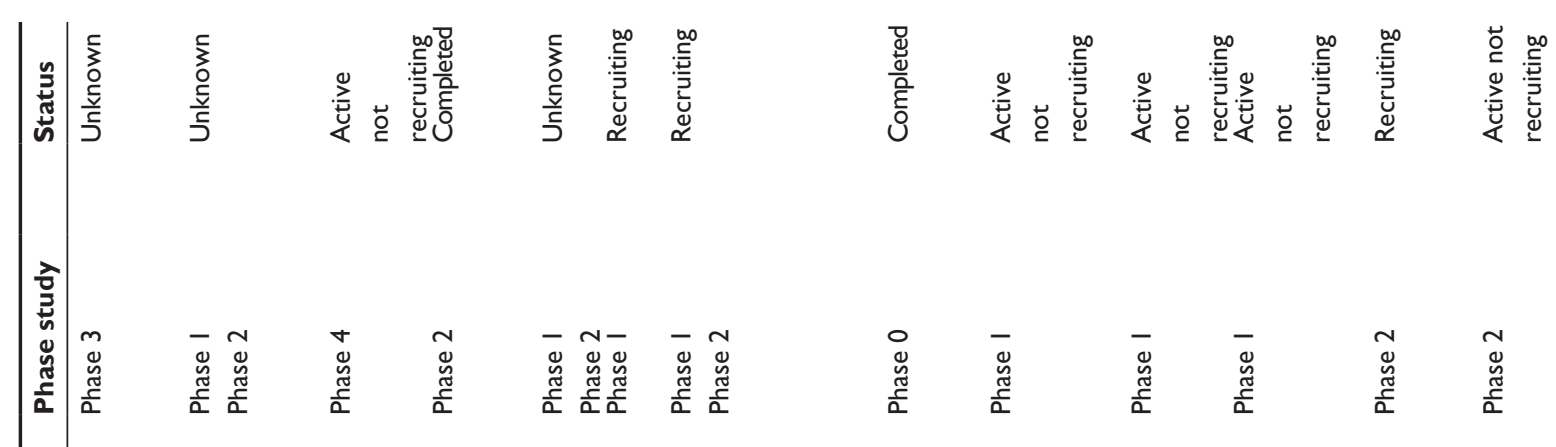

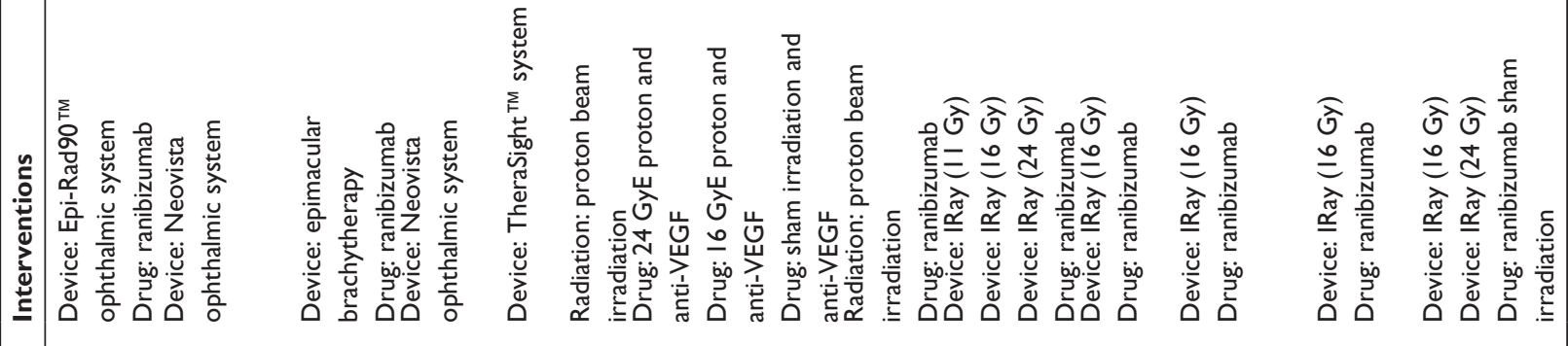

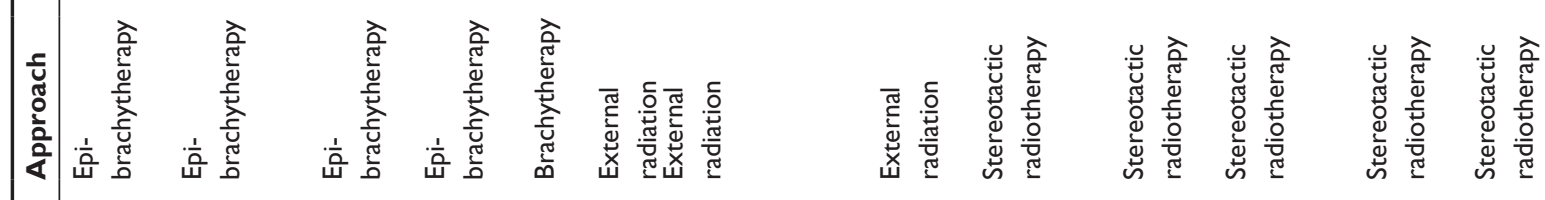

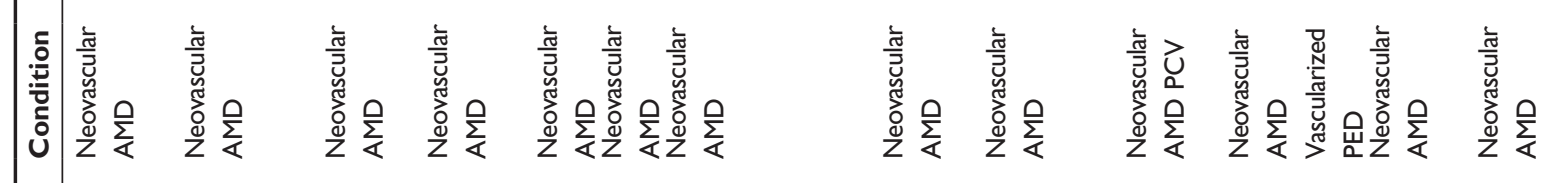

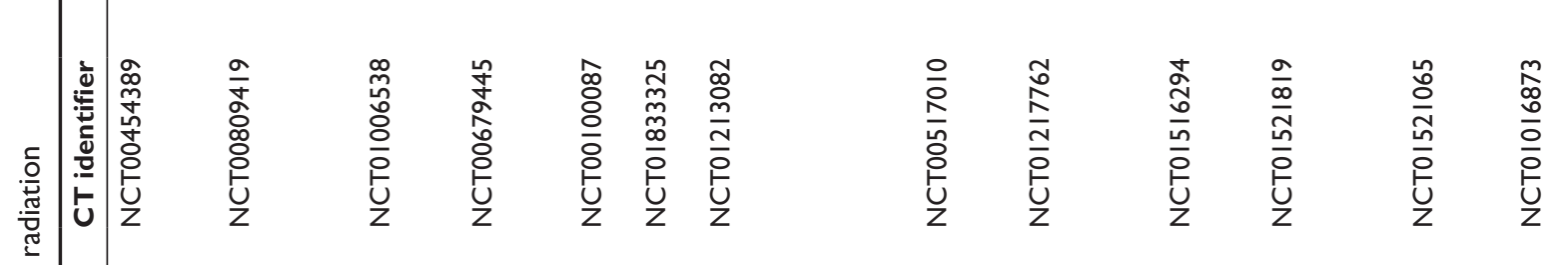

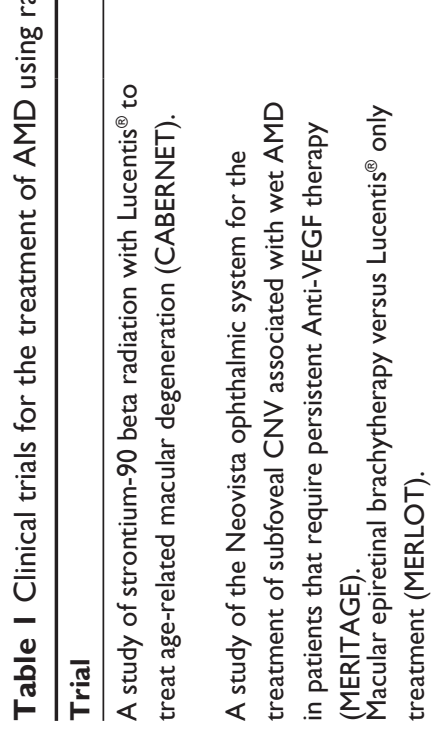

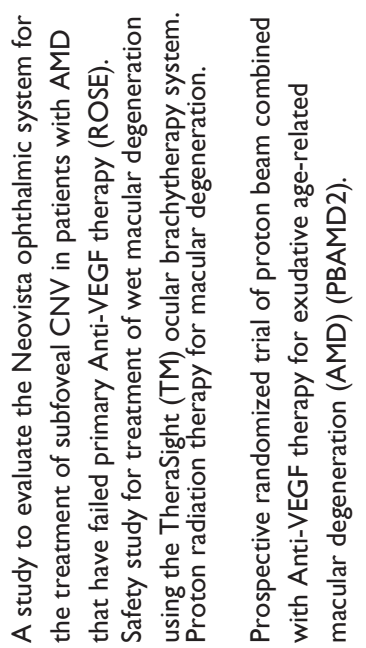

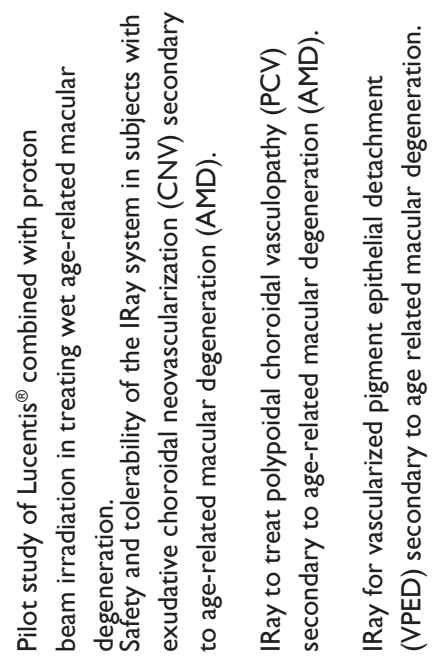

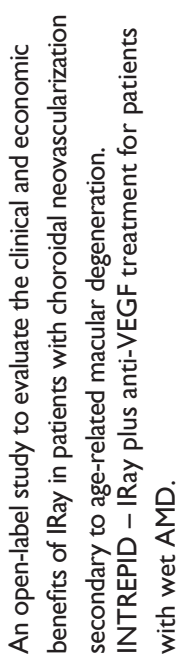




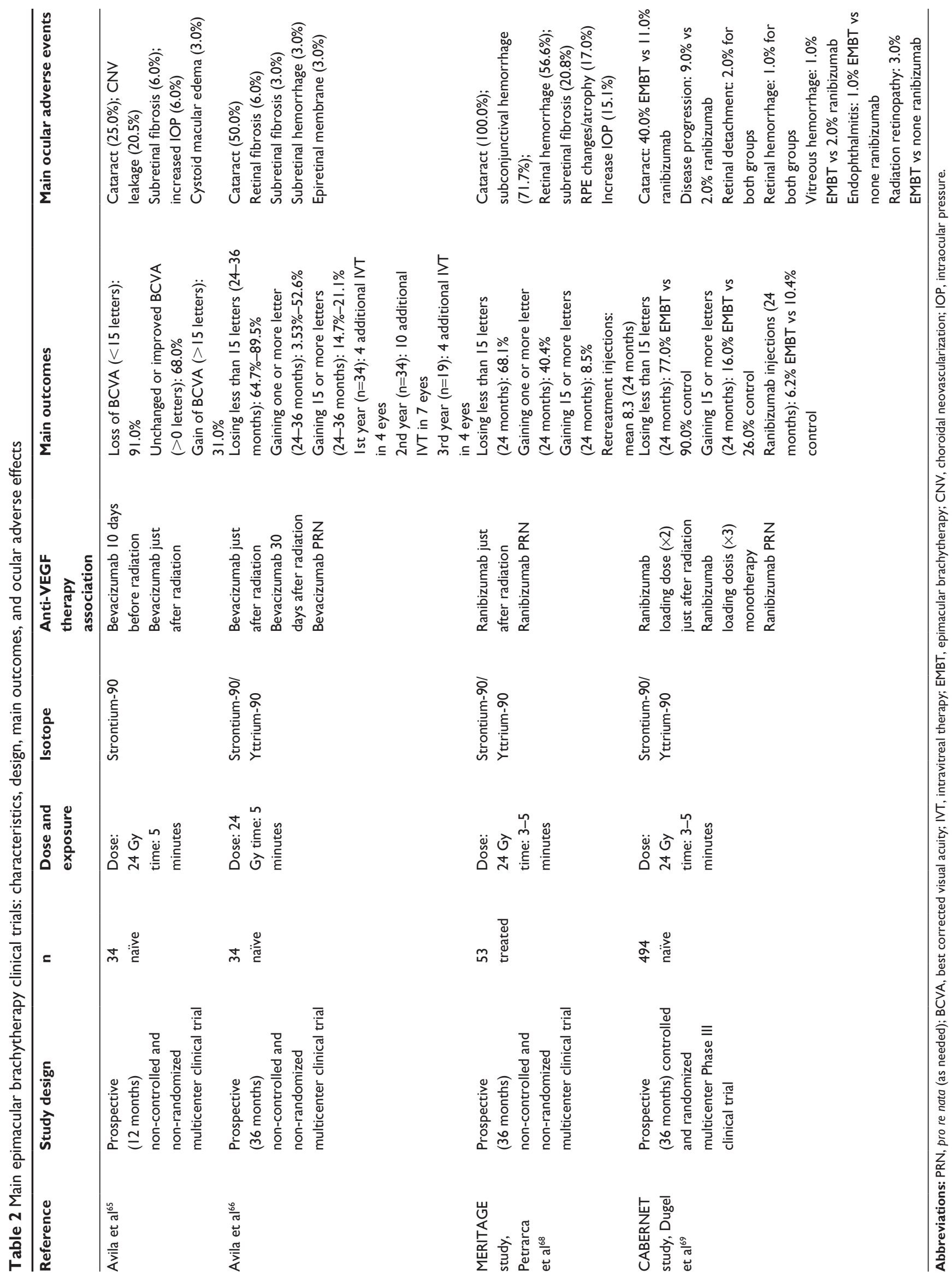


lesions, but not for predominantly classic and minimally classic lesions. The study also demonstrated that participants in the EMBT arm received less intravitreal therapy (IVT) (mean of 6.2 IVT) than those in the control arm (mean of 10.4 IVT). However, at least one serious adverse event occurred in 54\% of the EMBT arm (cataract) compared with $18 \%$ in the control arm (Table 2). There was also one case of mild non-proliferative radiation retinopathy. The authors concluded that at 24 months of follow-up the data did not support the routine use of EMBT for treatment of naïve wet AMD, despite an acceptable safety profile.

The MERLOT trial is a non-commercial, multicenter, randomized controlled clinical study in patients who have already commenced anti-VEGF therapy (Table 1). The objective of the study is to evaluate the safety and efficacy of focal delivery of radiation for treating subfoveal CNV associated with established wet AMD previously treated with anti-VEGF therapy. It is hypothesized that EMBT will reduce the frequency of anti-VEGF retreatments required by patients, whilst maintaining visual acuity. The MERLOT trial will enroll participants at several UK NHS hospitals. In total, 363 patients will be randomized in a 2:1 ratio, comparing epimacular brachytherapy and ranibizumab as required with ranibizumab monotherapy. ${ }^{40,58}$

\section{Conclusion}

The pathophysiology of wet AMD is complex and is not fully understood. Although anti-VEGF therapy has proven very successful, it is not effective for all patients, and the recommended therapy involves expensive monthly intravitreal injections and clinical follow-up, with a high cost for public health services. The use of combination treatments will hopefully improve on the results of current anti-VEGF agent therapy and may result in improvements in vision and more convenient dosing regimens. Beta radiation therapy has a rapid decline in dose with increasing distance from the radiation source, limiting exposure and the damage to adjacent normal tissue. EMBT offers very precise dosing but requires a surgical procedure, which often leads to cataract formation in patients with phakic eyes at baseline. The vitrectomy itself may be beneficial in treating AMD by limiting vitreomacular adhesion, increasing the level of oxygen available to the inner layers of the retina, and facilitating the radiation mechanism action on the cells. However, at the present stage of research, the results of the clinical trials carried out to date are insufficient to justify extending routine use of EMBT for the treatment of wet AMD, despite an acceptable efficacy and safety profile.

\section{Disclosure}

The authors report no conflicts of interest in this work.

\section{References}

1. Furtado JM, Lansingh VC, Carter MJ, et al. Causes of blindness and visual impairment in Latin America. Surv Ophthalmol. 2012;57(2):149-177.

2. Virgili G, Do DV, Bressler NM, Menchini U. New therapies for neovascular age-related macular degeneration: critical appraisal of current evidence. Acta Ophthalmol Scand. 2007;85(1):6-20.

3. Prokofyeva E, Zrenner E. Epidemiology of major eye diseases leading to blindness in Europe: a literature review. Ophthalmic Res. 2012; 47(4):171-188.

4. Rudnicka AR, Jarrar Z, Wormald R, Cook DG, Fletcher A, Owen CG. Age and gender variations in age-related macular degeneration prevalence in populations of European ancestry: a meta-analysis. Ophthalmology. 2012;119(3):571-580.

5. Spanish Eyes Epidemiological (SEE) Study Group. Prevalence of age-related macular degeneration in Spain. Br J Ophthalmol. 2011; 95(7):931-936.

6. Klein R, Klein BE, Knudtson MD, Meuer SM, Swift M, Gangnon RE. Fifteen-year cumulative incidence of age-related macular degeneration: the Beaver Dam Eye Study. Ophthalmology. 2007;114(2): 253-262.

7. Smith W, Assink J, Klein R, et al. Risk factors for age-related macular degeneration: pooled findings from three continents. Ophthalmology. 2001;108(4):697-704.

8. Friedman DS, Katz J, Bressler NM, Rahmani B, Tielsch JM. Racial differences in the prevalence of age-related macular degeneration: the Baltimore Eye Survey. Ophthalmology. 1999;106(6):1049-1055.

9. Kawasaki R, Yasuda M, Song SJ, et al. The prevalence of age-related macular degeneration in Asians: a systematic review and meta-analysis. Ophthalmology. 2010;117(5):921-927.

10. Gehrs KM, Anderson DH, Johnson LV, Hageman GS. Age-related macular degeneration: emerging pathogenetic and therapeutic concepts. Ann Med. 2006;38(7):450-471.

11. Lim LS, Mitchell P, Seddon JM, Holz FG, Wong TY. Age-related macular degeneration. Lancet. 2012;379(9827):1728-1738.

12. Biarnés M, Monés J, Alonso J, Arias L. Update on geographic atrophy in age-related macular degeneration. Optom Vis Sci. 2011;88(7): 881-889.

13. Lu M, Adamis AP. Molecular biology of choroidal neovascularization. Ophthalml Clin North Am. 2006;19(3):323-334.

14. Ferrara N, Mass RD, Campa C, Kim R. Targeting VEGF-A to treat cancer and age-related macular degeneration. Annu Rev Med. 2007;58: 491-504.

15. Olsson AK, Dimberg A, Kreuger J, Claesson-Welsh L. VEGF receptor signalling-in control of vascular function. Nat Mol Cell Biol. 2006; 7(5):359-371

16. Ng EWM, Shima DT, Calias P, Cunningham ET Jr, Guyer DR, Adamis AP. Pegaptanib, a targeted anti-VEGF aptamer for ocular vascular disease. Nat Drug Disc. 2006;5(2):123-132.

17. Ferrara N, Damico L, Shams N, Lowman H, Kim R. Development of ranibizumab, an anti-vascular endothelial growth factor antigen binding fragment, as therapy for neovascular age-related macular degeneration. Retina. 2006;26(8):859-870.

18. Rosenfeld PJ. New treatments for age-related macular degeneration. Lancet. 2007;370(9597):1479.

19. Browning DJ, Kaiser PK, Rosenfeld PJ, Stewart MW. Aflibercept for age-related macular degeneration: a game-changer or quiet addition? Am J Ophthalmol. 2012;154(2):222-226.

20. De Jong PT. Age-related macular degeneration. $N$ Engl J Med. 2006; 355(14):1474-1485.

21. Klein R, Cruickshanks KJ, Nash SD, et al. The prevalence of age-related macular degeneration and associated risk factors. Arch Ophthalmol. 2010;128(6):750-758. 
22. Chakravarthy U, Wong TY, Fletcher A, et al. Clinical risk factors for age-related macular degeneration: a systematic review and metaanalysis. BMC Ophthalmol. 2010;10:31.

23. Reynolds R, Rosner B, Seddon JM. Serum lipid biomarkers and hepatic lipase gene associations with age-related macular degeneration. $\mathrm{Oph}$ thalmology. 2010;117(10):1989-1995.

24. Barker FM. Dietary supplementation: effects on visual performance and occurrence of AMD and cataracts. Curr Med Res Opin. 2010; 26(8):2011-2023.

25. Ratnapriya R, Chew EY. Age-related macular degeneration-clinical review and genetics update. Clin Genet. 2013;84(2):160-166.

26. DeWan A, Bracken MB, Hoh J. Two genetic pathways for age-related macular degeneration. Curr Opin Genet Dev. 2007;17(3):228-233.

27. Montezuma SR, Sobrin L, Seddon JM. Review of genetics in age related macular degeneration. Semin Ophthalmol. 2007;22(4):229-240.

28. Ding X, Patel M, Chan CC. Molecular pathology of age-related macular degeneration. Prog Retin Eye Res. 2009;28(1):1-18.

29. Tuo J, Grob S, Zhang K, Chan CC. Genetics of immunological and inflammatory components in age-related macular degeneration. Ocul Immunol Inflamm. 2012;20(1):27-36.

30. Liu MM, Chan CC, Tou J. Genetic mechanisms and age-related macular degeneration: common variants, rare variants, copy number variations, epigenetics, and mitochondrial genetics. Hum Genomics. 2012;31(6):13.

31. Seddon JM. Genetic and environmental underpinnings to age-related ocular diseases. Invest Ophthalmol Vis Sci. 2013;54(14):ORSF28-30.

32. Zarbin MA. Current concepts in the pathogenesis of age related macular degeneration. Arch Ophthalmol. 2004;122(4):598-614.

33. Zarbin MA, Rosenfeld PJ. Pathway-based therapies for age-related macular degeneration: an integrated survey of emerging treatment alternatives. Retina. 2010;30(9):1350-1367.

34. Zarbin M. Pathogenesis of age-related macular degeneration. In: Bandello F, Querques G, editors. Medical Retina. ESASO Course Series. Basel: Karger; 2012;1:125-133.

35. Klein RJ, Zeiss C, Chew EY, et al. Complement factor H polymorphism in age related macular degeneration. Science. 2005; 308(5720):385-389.

36. Haines JL, Hauser MA, Schmidt S, et al. Complement factor H variant increases the risk of age-related macular degeneration. Science. 2005; 308(5720):419-421.

37. Gold B, Merriam JE, Zernant J, et al; AMD Genetics Clinical Study Group. Variation in factor B (BF) and complement component 2 (C2) genes is associated with age-related macular degeneration. Nat Genet. 2006;38(4):458-462.

38. Maller JB, Fagerness JA, Reynolds RC, Neale BM, Daly MJ, Seddon JM. Variation in complement factor 3 is associated with risk of age-related macular degeneration. Nat Genet. 2007;39(10):1200-1201.

39. Sivaprasad S, Hykin P. What is new in the management of wet agerelated macular degeneration? Br Med Bull. 2013;105:201-211.

40. Englander M, Kaiser PK. Combination therapy for the treatment of neovascular age-related macular degeneration. Curr Opin Ophthalmol. 2013;24(3):233-238

41. Stannard C, Sauerwein W, Maree G, Lecuona K. Radiotherapy for ocular tumour. Eye. 2013;27(2):119-127.

42. Silva RA, Moshfeghi AA, Kaiser PK, Singh RP, Moshfeghi DM. Radiation treatment for age-related macular degeneration. Semin Ophthalmol. 2011;26(3):121-130

43. Kirwan JF, Constable PH, Murdoch IE, Khaw PT. Beta irradiation: new uses for an old treatment: a review. Eye. 2003;17:207-215.

44. Rombouts C, Aerts A, Beck M, et al. Differential response to acute low dose radiation in primary and immortalized endothelial cells. Int J Radiat Biol. 2013;89(10):841-850.

45. Grossniklaus HE, Martinez JA, Brown VB, et al. Immunohistochemical and histochemical properties of surgically excised subretinal neovascular membranes in age-related macular degeneration. Am J Ophthalmol. 1992;114(4):464-472.

46. Emami B, Lyman J, Brown A, et al. Tolerance of normal tissue to therapeutic irradiation. Int J Radiat Oncol Biol Phys. 1991;21(1):109-122.
47. Gunduz K, Shields CL, Shields JA, Cater J, Freire JE, Brady LW. Radiation retinopathy following plaque radiotherapy for posterior uveal melanoma. Arch Ophthalmol. 1999;117(5):609-614.

48. A prospective, randomized, double-masked trial on radiation therapy for neovascular age-related macular degeneration (RAD study). Radiation Therapy for Age-Related Macular Degeneration. Ophthalmology. 1999; 106(12):2239-2247.

49. Archambeau JO, Mao XW, Yonemoto LT, et al. What is the role of radiation in the treatment of subfoveal membranes: review of radiobiologic, pathologic, and other considerations to initiate a multimodality discussion. Int J Radiat Oncol Biol Phys. 1998;40(5):1125-1136.

50. Lambooij AC, Kuijpers RW, Mooy CM, Kliffen M. Radiotherapy of exudative age-related macular degeneration: a clinical and pathologic study. Graefes Arch Clin Exp Ophthalmol. 2001;239(7):539-543.

51. Kishan AU, Modjtahedi BS, Morse LS, Lee P. Radiation therapy for neovascular age-related macular degeneration. Int J Radiat Oncol Biol Phys. 2013;85(3):583-597.

52. Hart PM, Archer DB, Chakravarthy U. Asymmetry of disciform scarring in bilateral disease when one eye is treated with radiotherapy. Br J Ophthalmol. 1995;79(6):562-568.

53. Ivanov VN, Zhou H, Ghandhi SA, Karasic TB, Yaghoubian B, Amundson SA. Radiation-induced bystander signaling pathways in human fibroblasts: a role for interleukin-33 in the signal transmission. Cell Signal. 2010;22(7):1076-1087.

54. Regillo CD, Brown DM, Abraham P, et al. Randomized, doublemasked, sham-controlled trial of ranibizumab for neovascular agerelated macular degeneration: PIER Study Year 1. Am J Ophthalmol. 2008;145(2):239-248.

55. Finger PT, Berson A, Ng T, Szechter A. Ophthalmic plaque radiotherapy for age-related macular degeneration associated with subretinal neovascularization. Am J Ophthalmol. 1999;127(2):170-177.

56. Jaakkola A, Heikkonen J, Tommila P, Laatikainen L, Immonen I. Strontium plaque brachytherapy for exudative age-related macular degeneration: three-year results of a randomized study. Ophthalmology. 2005;112(4):567-573.

57. Lommatzsch PK, Werschnik C, Schuster E. Long-term follow-up of $\mathrm{Ru}-106 / \mathrm{Rh}-106$ brachytherapy for posterior uveal melanoma. Graefes Arch Clin Exp Ophthalmol. 2000;238(2):129-137.

58. Petrarca R, Jackson TL. Radiation therapy for neovascular age-related macular degeneration. Clin Ophthalmol. 2011;5:57-63.

59. Canton VM, Quiroz-Mercado H, Velez-Montoya R, et al. 24-Gy lowvoltage X-ray irradiation with ranibizumab therapy for neovascular AMD: 6-month safety and functional outcomes. Ophthalmic Surg Lasers Imaging. 2012;43(1):20-24.

60. Cole CJ, Charteris DG. Cataract extraction after retinal detachment repair by vitrectomy: visual outcome and complications. Eye. 2009; 23(6):1377-1381.

61. Robison CD, Krebs I, Binder S, et al. Vitreomacular adhesion in active and end-stage age-related macular degeneration. Am J Ophthalmol. 2009;148(1):79-82.

62. Stefansson E, Landers MB 3rd, Wolbarsht ML. Increased retinal oxygen supply following pan-retinal photocoagulation and vitrectomy and lensectomy. Trans Am Ophthalmol Soc. 1981;79:307-334.

63. Jampol LM. Oxygen therapy and intraocular oxygenation. Trans Am Ophthalmol Soc. 1987;85:407-437.

64. Nordsmark M, Overgaard M, Overgaard J. Pretreatment oxygenation predicts radiation response in advanced squamous cell carcinoma of the head and neck. Radiother Oncol. 1996;41(1):31-39.

65. Avila MP, Farah ME, Santos A, Duprat JP, Woodward BW, Nau J. Twelvemonth short-term safety and visual-acuity results from a multicentre prospective study of epiretinal strontium-90 brachytherapy with bevacizumab for the treatment of subfoveal choroidal neovascularisation secondary to agerelated macular degeneration. Br J Ophthalmol. 2009;93(3):305-309.

66. Avila MP, Farah ME, Santos A, et al. Three-year safety and visual acuity results of epimacular 90 strontium/90 Yttrium brachytherapy with bevacizumab for the treatment of subfoveal choroidal neovascularization secondary to age-related macular degeneration. Retina. 2012;32(1):10-18. 
67. Dugel PU, Petrarca R, Bennett M, et al. Macular epiretinal brachytherapy in treated age-related macular degeneration: MERITAGE study: Twelve-month safety and efficacy results. Ophthalmology. 2012;119(7): 1425-1431.

68. Petrarca R, Dugel PU, Bennett M, et al. Macular epiretinal brachytherapy in treated age-related macular degeneration (MERITAGE): month 24 safety and efficacy results. Retina. 2014;34(5):874-879.
69. Dugel PU, Bebchuk JD, Nau J, et al. (CABERNET Study Group). Epimacular brachytherapy for neovascular age-related macular degeneration: a randomized, controlled trial (CABERNET). Ophthalmology. 2013;120(2):317-327.

\section{Publish your work in this journal}

Clinical Ophthalmology is an international, peer-reviewed journal covering all subspecialties within ophthalmology. Key topics include: Optometry; Visual science; Pharmacology and drug therapy in eye diseases; Basic Sciences; Primary and Secondary eye care; Patient Safety and Quality of Care Improvements. This journal is indexed on

\section{Dovepress}

PubMed Central and CAS, and is the official journal of The Society of Clinical Ophthalmology (SCO). The manuscript management system is completely online and includes a very quick and fair peer-review system, which is all easy to use. Visit http://www.dovepress.com/ testimonials.php to read real quotes from published authors. 